\title{
Professors' Experiences \\ With Student Disclosures \\ of Sexual Assault and \\ Intimate Partner Violence: \\ How "Helping" Students \\ Can Inform Teaching \\ Practices
}

\author{
Kathryn A. Branch, PhD', Rebecca Hayes-Smith, PhD', \\ and Tara N. Richards, MS $^{3}$
}

\begin{abstract}
As female faculty teaching classes on sensitive topics (e.g., Family Violence, Women and Crime, Victimology), we have received numerous disclosures of sexual assault and intimate partner violence (IPV) victimization from our students both in and outside the classroom. These experiences have caused each of us to reflect on our teaching practices within the classroom. When college professors receive disclosures from their students they have to develop strategies on how to effectively handle the disclosure, how to manage the classroom environment and assignments knowing that a survivor is in the course, and how to effectively handle their own emotional impact that may result from the disclosure. This paper explores the strategies that faculty report using when responding to disclosures by students and how receiving student disclosures can be used to inform teaching practices.
\end{abstract}

\section{Keywords}

qualitative research; sexual assault; victimology (general); intimate partner violence

\footnotetext{
'University of Tampa, Tampa, FL

${ }^{2}$ Central Michigan University, Mt. Pleasant

${ }^{3}$ University of South Florida, Tampa

Corresponding Author:

Kathryn A. Branch, PhD, University of Tampa, 40I W Kennedy Blvd, Tampa, FL 33606

Email: kbranch@ut.edu
} 


\section{Introduction}

More than two decades of research has documented that environmental and structural dynamics of college life place college women at a heightened risk for experiencing sexual and intimate partner violence (IPV) victimization (Armstrong, Hamilton, \& Sweeney, 2006; Cass, 2007; DeKeseredy \& Kelly, 1993; Fisher, Cullen, \& Turner, 2000; Humphrey \& White, 2000; Koss, Gidyez, \& Wisniewski, 1987). As a result, university administrators have invested in mechanisms aimed at making campuses safer for their female students such as campus security personnel and nighttime campus escorts (Fisher et al., 2000). In addition, many universities now provide sexual violence education programs for incoming students and advocacy and/or counseling programs for victims (Fisher et al., 2000). Although these initiatives are steps in the right direction, existing programming falls short of a comprehensive response to violence against college women.

Training and preparation for professors who may have students come to them for support postvictimization has received little consideration. Presently, anecdotal evidence exists whereby certain professors have referenced experiencing some level of disclosure from students (e.g., Adler, 1984; Durfee \& Rosenburg, 2009; MurphyGeiss, 2008) but to our knowledge, only one empirical study has been conducted on the subject (Hayes-Smith, Richards, \& Branch, 2010). Specifically, recent research has revealed that some female students are going to their professors as an outlet in which to receive support postsexual assault or intimate partner victimization, and such disclosures are causing a strain on unprepared or underprepared professors (HayesSmith et al., 2010). Hayes-Smith and colleagues (2010) found that in many cases professors were given little to no training on how to respond to student disclosures of sexual assault and IPV victimization even though disclosures often occurred numerous times over the course of professors' careers. Many professors in the sample also reported that they were unsure of students' motives and expectations in making these disclosures thus causing further confusion and stress for the professor receiving the information. It is our hope that the present research may provide a more contextualized understanding of the phenomena of student/professor disclosure and offer "next steps" for this important line of research.

\section{Literature Review}

\section{Female Student Victimization and the Search for Social Support}

Much of the research investigating the context of crime on college campuses has concluded that overall on-campus crime rates are significantly lower than those of their host or adjacent cities (Bromley, 1995; Hart, 2007; Volkwein, Szelest, \& Lizotte, 1995). One critical deviation from these findings is in regard to the rates of sexual violence. Research has suggested that whereas the rates of violent crime victimization of college students are significantly lower than those of their noncollegiate peers when violent 
crime is broken down by crime "type," rape is the only type of violent crime that is not experienced less often by college students (Hart, 2007). Therefore, college women may experience a more concentrated risk of sexual or gender-based victimization in their otherwise "safe" campus community (Fisher, Cullen, \& Turner, 2002). The combination of an elevated risk for sexual victimization as well as the vulnerability for repeat contact with perpetrators leaves college campuses uniquely dangerous for female students. Thus, in addition to the academic struggle customary to the university experience, many college women carry the heavy burden of victimization with them to class each day.

Oftentimes victims of sexual assault and IPV remain silent about their victimization because of the myriad of obstacles they must face in reporting such crimes. Victim barriers for reporting violence include embarrassment, fear of not being believed (Sable, Danis, Mauzy, \& Gallagher, 2006), or fear of being blamed for their own victimization (Yescavage, 1999). Indeed, research demonstrates that men who abuse women are hardly ever formally sanctioned and rarely admonished by their peers (Gamache, 1991; Siegel \& Raymond, 1992) whereas victims of gendered crimes are frequently portrayed negatively by the media, on campus, or at work (Sanday, 1996).

Very few victims of sexual assault use formal support agencies such as the police or hospitals (Golding, Siege, Sorenson, Burnam, \& Stein, 1989) and even fewer use only formal support providers (Starzynski, Ullman, Filipas, \& Townsend, 2005); however, research suggests that as many as two-thirds of sexual assault survivors disclose their assault to someone (Golding et al., 1989). Most often, survivors of gendered violence disclose their victimization to informal support providers such as family, friends, and significant others (Golding et al., 1989; Ullman, 1996). As many college students are separated from their usual support system they may seek alternative support providers.

Many college students, especially those between the ages of 18 and 24, are testing their independence from their parents, living away from home for the first time. As such, college women may not want to disclose sexual assault or IPV victimization to their families because it may make them feel like they have failed in taking care of themselves away from home. To illustrate the reluctance of female victims to report to their families, $44 \%$ of female students surveyed in the National College Women Sexual Victimization Study indicated that they did not report a completed rape to the school or police because they did not want their family to know (Fisher et al., 2000). Instead, college women may search for someone who is familiar and possesses the inherent supportiveness of a friend or family member - for many women this person could be their professor. Professors, especially in fields like criminal justice and sociology, teaching classes on family violence, may be viewed as especially attractive support systems for students because of their expertise and/or their perceived proclivity for withholding judgment (Durfee \& Rosenberg, 2009).

An added impetus for student disclosure may be the influence of gender and as such the most common disclosure scenario may be a female student disclosing victimization to a female professor. For professors, everyday social practices may propagate stereotypical gender roles by "doing gender" (West \& Zimmerman, 1987). Traditional 
gender roles prescribe that for women "doing gender" includes traits such as empathy, compassion, and giving (Hoffman, 1977) which may translate into female professors creating and establishing relationships with students, having an open door policy for students, and listening and caring when students come to them with problems or concerns. In addition, the role of traditional femininity obligates women to be responsible for providing emotional support to others (Bem, 1983). Accordingly, a national survey of college teachers reveals that nearly half $(46 \%)$ of female faculty members report attempting to assist in the emotional development of their students compared with 33\% of male faculty members (Lindholm, Szelenyi, Hurtado, \& Korn, 2005). The traditional female role also tends to be "relationship oriented" whereas the masculine role is focused on maintaining independence, personal autonomy, and a detached sense of emotional expression. In this vein, female faculty members describe spending more hours focused on their students-preparing for and teaching classes and advising students - than male faculty members (Lindholm et al., 2005). Most female faculty cite, "helping others who are in difficulty" and "being a good role model to students" as an essential professional goal (Lindholm et al., 2005).

In light of traditional gender roles, students may be more likely to approach their female professors and likewise female professors may be more likely to expend energy on building a rapport with their students. Indeed, existing qualitative research by Acker and Feuerverger (1996) reveals that female professors report "providing support for their students and colleagues" as one of their most important job-related responsibilities. One female professor participating in Acker and Feuerverger (1996) research described being used by her department as "a fire-extinguisher" for handling student crises (p. 408), whereas another reported "as a female you tend to be the shoulder to cry on" because "they're scared to go to their male supervisors" (p. 406).

"Doing gender" is a concept that may be supported in that female students may be more likely to reach out to their female professors (rather than their male professors) due to prescribed gender expectations of females being nurturing (West \& Zimmerman, 1987). Female professors may be viewed by their students as more open to disclosure due to perceptions of women being responsible for providing support. Therefore, leaving behind ones' support group, particularly ones' mother, a student may turn to a female role model such as a professor to seek guidance. In addition, female students may be "doing gender" in that they are more likely than their male counterparts to reach out for support postvictimization. For example, research suggests that female students are more likely than men to want to reach out for social support and assistance from a support provider (Day \& Livingstone, 2003; Ptacek, Smith, \& Dodge, 1994).

In addition to a professor's gender alone, female faculty members' may be more likely to receive more student disclosure than male faculty members because of the classes they teach. Female professors are six times more likely to teach women's studies classes and twice as likely to integrate readings on gender into their curriculum as their male counterparts (Astin, Dey, \& Korn, 1991). They are also more likely to attend workshops on the subjects of gender, race, or culture (Astin et al., 1991). In turn, as part of their teaching pedagogy, female professors may be more likely to create a safe 
space for openly discussing sensitive topics. Indeed, female professors are more likely to report, "enhancing their student self-understanding" as a pedagogical goal (Astin et al., 1991). In addition, faculty teaching in particular disciplines whose curricula focus on various forms of violence (e.g., criminology and criminal justice) may be more likely than other disciplines to experience victimization disclosures from their students.

In a survey of campus administrators only about half of all schools - including three out of 10 public 4-year schools - provided training to faculty and staff on how to respond to disclosures of sexual assault (Karjane, Fisher, \& Cullen, 2002). This research suggests that no more than half of all professors receive any training for crisis intervention, sexual assault advocacy, and/or the victim recovery process - and that those that do, likely do so both independently and unofficially. In turn, professors can be left unprepared for a student's disclosure, which may have a profound effect on both the survivor and the professor. Research has suggested that survivors are more likely to disclose intimate information when they believe the disclosure will result in personal benefit (e.g., feeling better) or the deterrence or prevention of future crimes (Bachman, 1998; Feldman-Summers \& Norris, 1984). If the initial disclosure does not provide comfort or relief to the survivor, he or she may not seek the needed assistance and support (Ahrens, 2006). Existing research demonstrates that survivors who are experiencing higher levels of distress are more likely to disclose (Golding et al., 1989; Ullman, 1996) suggesting that when students turn to professors for help they may be in need of immediate and meaningful support, rendering it critical that the professors are qualified to and comfortable with providing said support.

\section{Student Reactions to Classroom Material}

A professor who vacillates between their formal role as an educator and an informal support provider for students could be helpful or harmful in their reaction to a disclosure of sexual assault or IPV. Recently, scholars have provided a guided breakdown of suggestions for how professors could address these situations (Durfee \& Rosenberg, 2009; Murphy-Geiss, 2008). Arguing for a feminist pedagogy focused on advocacybased counseling, these scholars assert that it is important to (a) clear a space for listening to students, (b) show a readiness to listen, and (c) engage in active listening techniques (Durfee \& Rosenberg, 2009). Also, Murphy-Geiss (2008) suggests that the traditional instruction models of reading and lecture are not appropriate when teaching a course on the issue of domestic violence. Instead, attention should be paid to multiple pedagogies that highlight emotionally engaging methods and realistic situations. Murphy-Geiss (2008) suggests four components to engage students when instructing on this subject such as, (a) controversial readings; (b) particularly powerful films; (c) expert guest speakers who work with victims and/or perpetrators of domestic violence, and, perhaps most importantly; and (d) observations in domestic violence courts. The above suggestions are timely, and we aim to add to the relevant literature.

In the exploratory study discussed herein, we conducted open-ended interviews with a sample of 30 professors regarding their experiences with student disclosures of 
sexual assault and IPV victimization. We were all drawn to this project because each one of us has experienced a disclosure and felt underprepared in responding to our students. Not surprisingly, each of us has modified our own teaching practices in light of the realization that we are likely to have victims/survivors in our classrooms. Through this project we intend to open the dialog between professors who have received disclosures of sexual assault and/or IPV from students and the wider academic community. In doing so, we hope to assist professors who might not yet realize that students may disclose very sensitive information in their classes (or outside classes), to let professors who have received this type of information know they are not alone in these situations, to convey the importance of adequately preparing educators for the receipt of such disclosures, and to provide information on how some faculty report using disclosures to inform teaching practices.

\section{The Current Study}

The current research is guided by several questions. First, are students disclosing to professors? Second, in which classes are the disclosures occurring, and what kind of violence is being disclosed (sexual assault or IPV)? Third, how are the disclosures unfolding (where, when, and how)? Four, how are the disclosures affecting the teaching practices of professors? Five, what resources are professors saying they need to adequately address this issue?

\section{Method}

\section{Participants}

This sample included 30 professors and instructors who had received a sexual assault or IPV victimization disclosure from a student at some point during their career. We concluded data collection at 30 because we had reached data saturation. Data saturation is explained as the process in qualitative research where no new themes are emerging from the data indicating an appropriate point for the data-collection process to be stopped (Kvale, 1996; Lofland, Snow, Anderson, \& Lofland, 2006).

Twenty-seven of the 30 participants in this study were woman. All participants identified themselves as White. At the time of the interview, the average age of the participants was 44.7 years $(S D=13.46)$, and said participants ranged in age from 27 to 68 years. The average years of teaching experience for the participants was 12.15 $(S D=11.27)$ and ranged from 1 to 37.5 years. The sample consisted of equal numbers of tenured $(n=15)$ and untenured faculty $(n=15)$. Untenured professors included four tenure track professors (who had not yet received tenure), two doctoral students, one adjunct, one instructor, one visiting instructor, one participant who taught courses but whose main responsibilities were administrative, and six participants who did not specify their job title. These 30 professors and instructors taught at 30 different institutions and taught in a variety of departments including criminology, criminology and 
criminal justice, psychology, English, literature, political science, gender and women's studies, women's studies, and sociology. In addition to participants from the United States, faculty from the United Kingdom, Canada, and Australia were included in the sample.

\section{Design}

As the present research was unfunded, email solicitation was chosen as a sampling strategy. Professors and instructors who had received a disclosure of sexual assault or IPV from a student were recruited through a solicitation email posted on two professional criminology listservs. This email solicitation allowed the present research to recruit participants from Universities throughout the United States as well as outside the United States. The solicitation was as follows:

Has a student disclosed that he or she was a victim of dating violence and/or sexual assault? College students are an especially vulnerable population to the occurrences of sexual assault and intimate partner violence and may turn to their professors for help. If you have had a student disclose to you we would like to talk with you about your experience.

Participants responded to the solicitation through an email account set up solely for the project. Anyone who responded to the solicitation email was provided with an electronic copy of the informed consent and was scheduled for a telephone interview.

The researchers employed a qualitative interview approach to gain insight into the experiences of the respondents. Qualitative research attempts "to make sense of, or interpret, phenomena in terms of meanings people bring to them" and "describe routine and problematic moments and meanings in individuals' lives" (Denzin \& Lincoln, 2003 , p. 5). Qualitative methodology allowed us to gather rich, contextual descriptions of the disclosure process from participants' own viewpoints. Qualitative data were obtained from open-ended telephone interviews. Hutchinson and Wilson (1994) state that participating in qualitative interviews can provide a helpful setting for participants to reflect on and digest their experiences. We engaged the participants, shared information, and feelings and cooperated in constructing meanings together (DeVault, 1990).

The interview consisted of 39 questions that sought information about the disclosure, the participant's feelings and reactions to the disclosure, the experience of assisting the survivor, and the affect of the disclosure on the participant (see appendix for full interview protocol). As is common in qualitative research, not all questions were asked of each participant as too many questions risk cutting off the natural flow of conversation (Kvale, 1996). In the interview process, many questions were answered without being explicitly asked as the conversation naturally progressed. The interview duration ranged from 17 to $74 \mathrm{~min}$, and the average was $30.23 \mathrm{~min}(S D=12.71)$. 
The interviews were conducted by telephone during the summer of 2009 . Before the interview began, oral consent was obtained from each participant to participate in the study and to permit the recording of the conversation. The informed consent form emphasized that information given was completely anonymous and would not be linked with the participant's identity or institution in any manner. The informed consent form further stipulated that taping was optional and specifically asked permission to tape the interview. No participants refused the recording of their interview. The recording device with the audio files was kept in a locked file cabinet and was transcribed within $48 \mathrm{hrs}$, after which the audio files were erased. Transcribed interviews did not contain any identifying information.

\section{Analysis Procedures}

In accordance with traditional qualitative methodology, we "started where we were" and conceived the research questions based on our personal experiences with the topic (Lofland et al., 2006). We conducted the interviews, transcribed the majority of the interviews, and carefully read through the transcriptions/living conversations (Kvale \& Brinkmann, 2009). We analyzed the data by hand, as opposed to using a qualitative software package, to engage in all levels of the analysis. For the first level of coding, each coder reviewed the answers to questions individually and identified initial themes or concepts. Then, the coders met and discussed the initial themes selected by each coder for each question and response. Some questions/answers were collapsed into overarching categories and major themes were agreed on for the remaining questions.

Although information about the assault and disclosure experiences emerged throughout the interview, several open-ended questions in particular were useful in generating data related to the goals of the current study. These questions prompted the respondents to share information about the disclosure and their reactions to the disclosures. Once the transcripts $(n=30)$ were coded, the open-ended responses were analyzed in an effort to discover the range of responses pertaining to participants' experiences receiving student disclosures in addition to the effects of said disclosures on the participants' teaching practices.

\section{Results}

\section{Student-Professor Disclosures}

Whereas we cannot ascertain how often student disclosures occur among all faculty, or even among all social science faculty, we did ask if participants had received numerous disclosures over time. Receiving numerous disclosures may be indicative of a need for instructors to create a policy of dealing with disclosures. Indeed, $93 \%$ of the participants reported receiving multiple disclosures of sexual assault and/or IPV throughout their teaching careers. For example, when asked "have you had more than one experience?" one untenured female participant who had been teaching for 
3 years reported, "Well I mean I think I had about five disclosures directly to me this past year."

Overwhelmingly, most participants indicated that disclosures came from current students $(77 \%)$ and further noted that it was common for disclosures to occur, whereas students were taking a course on victimization issues (e.g., family violence) or gender issues (e.g., women and crime). The majority of participants indicated that every disclosure they had received thus far had been either IPV (41\%) or sexual assault (59\%). Almost all of the disclosures were from a female student $(n=29)$ rather than a male student $(n=1)$. The one male student had not personally experienced an assault but was a secondary victim. In addition, $31 \%$ of the participants felt that the last student who had disclosed to them was in crisis at the time of the disclosure.

We asked participants where their most recent disclosure occurred as the reaction to the student's disclosure was likely to be different if the student disclosed in class as opposed to in the participant's office. Several participants reported initiating contact with a student after he or she noticed the student starting to slip in their work or attendance; however, for the most part, the disclosing student initiated contact with the participant. Participants reported different methods used by students to initiate contact. Participants explained that some students came up to talk to them after class (30\%). For example, one participant described receiving a disclosure after showing a video on date rape in her women and violence class. The professor explained,

She [the student] actually came up and talked to me after class and she had said that she had been a victim of date rape ... part of her concern was that a lot of people were not taking it very seriously like this is something that would never happen to me [other students].

Participants also reported that students came during office hours (30\%) and contacted them via email (20\%). Other participants indicated that students described the victimization in an assignment, whether it was written on a discussion board or spoken out loud in class $(16 \%)$. One participant who had a student disclose in the middle of a workshop explained,

She was talking about being a victim and she was still a victim and she didn't like people to refer to her as a survivor or something and that really touched me and made me upset and wanting to do something.

Another participant who had a student disclose in an assignment explained,

And this is where it's hard ... It's hard because I'm doing all things via email ... sometimes telephone ... every once and a while they'll come in and speak with me. He seemed to be okay with it but I'm always concerned that they're not okay. 
The remaining participants stated that students contacted them via the telephone $(3 \%)$.

When participants were asked if students had asked for consideration with grades or assignments due to their victimization, almost all respondents (93\%) said that the disclosing student did not ask for consideration with grades or assignments. For example, a woman tenured faculty member who had been teaching for years and had numerous disclosures said that the particular student she was talking about had not asked for consideration. Her exact statement was

No, no, no not at all, not at all. That's the interesting thing. I've had other students who've asked for that but no, not her. She was determined to do her work. She did do her work. I did say to her without her asking . . . I said if you need more time let me know.

Several of the participants (20\%) did offer some type of accommodation with assignments but not at the request of the student. One participant explained, "I was asked [by administration] if I would be willing to give her assignments from home and I said absolutely."

\section{How Receiving Disclosures Informed Teaching Practices}

The majority of participants $(87 \%)$ described ways in which receiving student disclosures informed or affected their teaching practices and negotiation of the classroom environment. We will focus on the themes that were most pervasive in the participants' responses. There appeared to be two different pedagogies that participants used. As a result of receiving disclosures, participants reported either engaging in teaching practices that appeared to facilitate and encourage student - professor disclosures or engaging in teaching practices that appeared to minimize student-professor disclosure and referred the student elsewhere.

Practices that facilitated or encouraged student-professor disclosure. Participants (23\%) reported feeling it was important to create a safe environment in the classroom. For example, one participant, a sociologist exclaimed,

I don't know! I try to create a kind of nurturing, safe place for students to express kind of anything . . . I mean I really work hard at creating that kind of climate so I think that maybe I sort of invite them in.

Whereas a participant who had been teaching for 13 years observed, "I think that I um I both work harder now I think to create an open environment so people can disclose now."

Participants (20\%) also explained that they took a proactive approach in their classrooms and reached out to students they noticed were falling behind or were distressed. One participant reported that after a student started missing classes he asked the student to come to his office. He told the student 
I'm not sure what's going but you're a great student like we can find a way. I'm not sure what is going on in your private life but we can find a way of making sure that you finish this class.

Some participants (16\%) opted to use papers, assignments, and/or service learning projects as an option for students to work through their victimization experience. One professor explained,

... she [the survivor] asked if she could write about her experience. I said sure. I said that a good catharsis for you. So I said you know let's do some research, some academic research, let's discuss the theories, let's discuss the cases and then ... I said no one reads your paper but me. I said sure go ahead.

Another participant explained that she

started using journals in the women and crime class maybe four or five years ago ... it has been cathartic for students and reading them I realize that for a lot of students it's been a place to process but it also has opened my um . . . you know it opens my eyes and my opportunities to reach out.

Others used service learning projects or community service projects as teaching tools after receiving disclosures. One professor engaged her classes through the Clothesline Project. ${ }^{1}$ She described the experience as being "a really powerful experience usually for my students and it's something that maybe they wouldn't do on their own." She went on to say that the students' experience with the Clothesline Project

generates a lot of discussion in my class about victimization as you can imagine because you know a lot of people will say um I knew someone who was a victim or I was a victim and I think this was great. It was really powerful.

A few participants $(10 \%)$ experience with disclosures appeared to make them emphasize to students their open door policy. One participant reflected,

I can tell you that I will spend a lot more time talking about the sensitive nature of victimization and really expressing to students that if they themselves or anyone that they personally know has been victimized by the kind of topics that we will cover they are more than welcome to come to me.

Practices that minimized student-professor disclosure. Under the second theme, participants reported changing their teaching practices in ways that would potentially minimize their receipt of disclosure. Participants (17\%) described giving warnings of topics and resources in the course syllabi as a result of receiving past disclosures. One participant explained, "If you can anticipate it you can minimize the degree to which this is 
going to be a problem." Unlike the theme above where one participant explained her open door policy, this participant warned about the sensitive nature of the class and if someone is not ready to handle the material they should consider not taking the course.

Participants $(17 \%)$ also reported attempting to manage or screen out material that they believed might trigger survivors and lead to disclosure. One participant explained, "I'm certainly more cautious about what topics I allow" whereas another added,

I can remember one time someone telling me they had their class watch Monster that movie and I was saying that I don't know if I would show that in my class and they were asking me why and I said well I know that that semester I had three sexual assault victims and there's a pretty graphic sexual assault scene in that movie.

Participants $(10 \%)$ warned students that the classroom was not a safe environment for disclosure. One participant described telling her students,

You know this is not necessarily a safe environment in the classroom so you need to be very careful thinking about what you disclose and I know professors that actually instruct their students not to make any personal disclosures in class ...

\section{Participant Recommendations on Disclosure Response}

We requested recommendations/suggestions from participants for resources professors need to adequately address the issue of students disclosing sensitive information. These recommendations for responding to student disclosures as well as ideas for implementing initiatives to assist professors in helping their students were as follows: (a) to familiarize oneself with campus and community resources, (b) to listen, (c) to invite guest speakers to classes, (d) to have more resources to support faculty members and to have easy access to those provided, (e) to have training for responding to victims, and (f) to have the opportunity to debrief after receiving a disclosure - similar to advocates opportunity for "self-care." We will now explore each recommendation in further detail.

First and foremost, participants encouraged professors to familiarize themselves with their university and community resources regarding sexual assault and IPV. Preparation and planning were strongly emphasized in participants' responses. Specifically, one participant stated, "I think certainly instructors need to be aware of the resources that are available on their campus." Whereas another participant reflected, "I really think that they [professors] need to be aware of both on and off campus resources."

Second, participants highlighted the significance of listening - really listening - to students when they disclose accounts of victimization. One participant suggested, "Listen. Sometimes I think really what they want is somebody to listen to them without judgment, you know"; whereas another indicated, "You have to listen. You have to listen. You have to listen to what they have to say." Believing the accounts shared 
by students was also deemed by participants to be a critical component of the listening process. For example, one participant advised, "I would say always believe them. Don't ever question the experience. ..."

Third, participants suggested inviting a guest speaker to come and talk to classes about sensitive topics like sexual assault and IPV. One participant revealed, “... we've got a group that talks about suicide and we've got one that does sexual assault. Faculty have gotten a little more into the groove about bringing people to talk to the class." In addition to assisting survivors, guest speakers can be a great way to educate nonvictim students about the realities of sexual assault and IPV. Moreover, when meeting knowledgeable guest speakers, professors have the opportunity to make connections with practitioners in the field so that they have a "go to" person in the event of future disclosures by students. In this vein, some participants were cognizant of their own limitations and recommended that others acknowledge the same. One participant stressed that professors can "allow themselves to be there for the student to a certain extent ... we're not counselors. ..." whereas another participant stressed, "I think it's important to recognize that you don't know it all and you are not a counselor."

A fourth observation of participants identified the need for support when handling student disclosures. Participants requested easily accessible information and uniform policies for handling disclosures within their universities. One participant simply stated, "Information is better than anything else." Another participant described their search for resources like this,

I found the links to the counseling service and the advocacy program and found out about the psychology department and things of that nature, but that should all be listed in some type resource file for instructors so they can link their students to those services.

Another participant went on to say,

I think on the top of my wish list would be to inform faculty members that this is a reality. It's not that it's likely to happen. It's when will it happen and really explaining to them how to handle that.

Participants also recommended standardized training for responding to disclosures. When asked what could help them respond better to student disclosures, one participant revealed,

Yeah actually I've often felt that I need some training. This has become such a regular part of my job, and you know, I talk to my colleagues about it. I'm not really sure I'm handling it the right way.

whereas another stated emphatically, "Training training training. I wish my department had better prepared me to take over the Victimology course." 
Finally, participants proposed a debriefing mechanism for professors after they receive a student disclosure. One participant explained, "I found talking to a kind of confidential advisor really helpful. ..." Another participant suggested,

I think it would have been helpful if I could have talked to the counselor after it was done. I did actually talk to a professional about it but having had that option at school rather than just through my own connections would have been helpful like knowing that I could have gone to someone.

\section{Discussion and Implications}

The purpose of the current study was to open up dialogue regarding faculty experiences with student disclosures of sexual assault or IPV, to build on existing literature, and to provide information on how some faculty report using disclosures to inform teaching practices. As scholars and activists we must recognize that the affect of sexual assault and IPV victimization on our college campuses has ripple effects throughout the college campus community and that all those affected deserve our validation and support. We attempted to gather contextual descriptions of professors' experiences with the disclosure process from their own viewpoints. Although we cannot definitively establish the breadth of student disclosures to professors, several key findings emerged from our analysis of the interviews. We believe that these findings may be used to inform both professors' teaching practices and university policies on violence against women.

The majority of faculty members in this sample reported receiving numerous student disclosures of sexual assault and/or IPV victimization throughout their careers. A pedagogical issue has emerged in light of this realization as some may argue that negotiating the disclosure process with a student is not part of a professor's job description. Anecdotally speaking, we have had conversations with colleagues where we were specifically told that faculty should not be discussing personal issues with students. It would appear that participants in our sample also struggled with this issue. As mentioned above, some participants reported changing their teaching practices after receiving disclosures of sexual assault and IPV to create more openness and facilitate disclosures. Other participants changed their teaching practices after receiving disclosures to minimize their receipt of disclosure.

The reality is that some students are coming to their professors for help postassault and in some cases not just once, but according to the majority of participants in the current sample, multiple times. Future research could examine students' reasons for approaching their professors to disclose and try to determine what students are looking for from their professors when they disclose. In addition, future research could address how a professor might handle a disclosure if both the victim and offender are in their class. This information could help to prepare faculty for disclosures and better equip them in guiding student victims. As faculty never know when a student may disclose sexual assault or IPV, it is important that professors are made ready to respond. 
The current study's finding that disclosures of victimization were primarily from female students to female faculty should not be ignored. We must ask whether male students are disclosing victimization and whether male professors receive disclosures at the same rate as female professors. As mentioned above, research does suggest that female students are more likely than their male counterparts to seek social support (see Day \& Livingstone, 2003; Ptacek et al., 1994). The current exploratory study used a convenience sample. Future research could use a random sample of faculty to examine whether there are distinct gender differences among student disclosures and professors' reactions to these disclosures.

Our results illuminated different methods by which students contacted their professors to disclose victimization. Sometimes students disclosed in an email or over the phone disallowing participants the opportunity to fully appraise the situation via body language, or in the case of email, even tone of voice. In addition, some participants reported confusion on whether or not to follow-up with a student in person after receiving a disclosure over the phone or via email. In some cases disclosures came at difficult times for professors such as, after a long lecture or right before class time. However, the participants talked about the importance of being willing to take the requisite time to listen to students each and every time a student chooses to disclose such personal information. This suggestion is especially valuable in light of research findings that suggest a poor response to a disclosure of sexual assault may have a lasting negative affect on the survivor (Ahrens, 2006). It may be important for faculty to consider creating time before and/or after class in the event that a student may need to talk, especially in the case of courses focused on victimization or other sensitive topics.

Some participants noticed a slip in the student's work and approached them about the change in their academic behavior. This initiates an interesting pedagogical question: Is it within a professors' role to seek out a possible student disclosure? If it is not, is it possible that victimized students are simply slipping through the cracks? On a related note, it could be argued that a professor cannot remain objective whereas grading an assignment in which a student has disclosed sexual assault or IPV. Consider how devastating a student may feel if given a poor grade on an assignment where they disclosed such sensitive information. As educators, it may be important to reflect on assignments that may elicit disclosures of victimization and how these assignments will be graded given the potential affect on a survivor.

The current research also pointed to the fact that many of the students who approached their professors did not ask for consideration with grades or assignments. This is an important finding. Sometimes we hear about how faculty members may think students are lying about important life circumstances to get out of an exam or to get an extension on an assignment. We certainly have thought this ourselves. Our findings, however, do not support this assumption. This should not be surprising given the low number of false reports of rape compared with other crimes (Fisher et al., 2000). Whereas this type of information may seem like common knowledge to a criminal justice or sociology professor, it is clear that society maintains a lot of negative stereotypes regarding rape and rape victims. Some professors may not have received 
education on sexual victimization to dispel myths and stereotypes and therefore may themselves hold onto some of these harmful stereotypes. It is extremely important for professors to not suggest that the student may be lying regarding sexual assault or IPV victimization, as research indicates that the student may in turn never tell another person (Ahrens, 2006). Previous research has documented that the disclosure response affects a survivor's ability to cope and her recovery process (Ahrens, 2006). Therefore, the professor's reaction to the disclosure could be imperative to the student survivor's recovery - especially if the professor is the first person, the student has confided in regarding their experience (Durfee \& Rosenberg, 2009).

Many of our participants admitted confusion on whether their university had policies and resources for sexual assault and IPV victims/survivors. This finding highlights an opportunity for Universities to target both students and faculty simultaneously when educating about resources available for victims of violence. Currently, it appears that many college campuses focus primarily on educating students whereas support sources likely to come into contact with victims/survivors (such as a professor) are overlooked (Fisher et al., 2000). In addition to students, professors need to be informed about resources available for victims of violence. For example, resources could be linked to university websites and faculty could be given a referral list of counselors, advocates, shelters, and support groups to contact when students disclose to them. Armed with this information, professors could include a paragraph in their syllabi that provides students with the number for resources and counseling services should they need them.

Whereas our research only focused on victimization, particularly gendered, there are a myriad other forms of disclosures that could occur. For example, future research could address the implications of "coming out," of death of a close family member, other forms of victimization, depression, and any other major life issue that students may disclose to their professor. Important questions include whether the effects on professors are the same, who is most likely to receive disclosures, and what outcomes are the students seeking when they chose to disclose.

The majority of the participants in the current sample explained that they believed the subject matter of the classes they were teaching (e.g., family violence and victimology) might have triggered student disclosures. Some participants explained that some student survivors took their course on sensitive topics not knowing certain material would be discussed in class and/or not realizing how discussing sensitive topics would affect them. Faculty can prepare students by being specific in their syllabi about when the topic will be discussed in class. If the class material is indeed serving as a potential trigger for student disclosures, faculty members teaching courses on sensitive topics (e.g., family violence and victimology) could take Murphy-Geiss's (2008) suggestions and approach the course and the course material in an interactive manner. For example, faculty may consider adding a service-learning component to their class. This could be beneficial for both nonsurvivors and survivors in the course by exposing the prevalence of violence against women and offering a way for students to process their victimization experience. The specifics of the requirement would be left up to the 
discretion of the individual professor but could include activities like participation in a Take Back the Night event on campus, participation in the Clothesline project, working with a rape crisis counseling center, working with a domestic violence shelter, and so on.

Many of our participants indicated that they did not feel they were adequately trained in what to do if a student came to them to disclose these forms of violence. Participants explained that others in their department and or/ the university administration do not take student— professor disclosure seriously. Others felt that they are their department's "go-to person" for handling students' personal issues. As previously discussed, HayesSmith et al. (2010) found that student disclosures are causing work-related strain or stress on unprepared or underprepared professors. Instead of isolating professors who respond to student disclosures, we should attempt to create an atmosphere whereby these professors are supported by their colleagues and administrators and prepared for student disclosures. This can be directly achieved by implementing standardized policies and training for student—-professor disclosure. Whereby, when disclosures occur professors will be able to reflect on the experience with other professors, such as in a support group. Then professors will feel supported and be better prepared when students do come forward to disclose.

Directly related to faculty support and training is the need for a mechanism for debriefing a professor after he or she receives a disclosure from a student. The existence of vicarious trauma is well known in the counseling, advocacy, and social work communities. The importance of "self-care" is imperative in beating the burnout caused by hearing multiple stories of trauma and abuse (Skovholt, Grier, \& Hanson, 2001; Wasco, Campbell, \& Clark, 2004). Professors who receive disclosures of victimization from students have both a need for and a right to receive care and support. University administrator's could help facilitate professor self-care by promoting the on-campus counseling or advocacy center as well as providing nonuniversity support for professors who do not want to use on campus services for fear of seeing students or colleagues. This finding highlights an opportunity for universities to garner professor support and participation in their campus programming. Indeed, many of the participants stopped the interviewer before, during, or after the interview and mentioned they were very glad to have an opportunity to discuss this issue with someone and advance recommendations on the student- professor disclosure process.

\section{Conclusion}

Overall, these results suggest that sexual assault and IPV victimization in the lives of college students may ultimately become issues in the lives of faculty. Particularly, when teaching about gender or violence professors may want to be prepared for the potential affect that the material may have on students in the class. Depending on a professor's comfort level and/or training they may use techniques that encourage disclosures, attempt to divert them to resources, or even both. We think that the discussion about proper teaching practices regarding victimization will be an ongoing one with different stances about pedagogy. It is our hope that future research will examine specific practices used by faculty and the impact of those practices on students. 


\section{Appendix}

\section{Interview Schedule}

1. How long have you been a professor?

a. Are you tenured?

b. At the same university?

c. Which department?

d. Courses taught?

As you probably realize, I am interested in hearing about your experiences with students disclosing information to you about their personal experiences with dating violence or sexual assault.

2. To begin, I want to open up with, why did you choose to participate?

Tell me about your most recent experience with a student disclosing their experience with sexual assault or dating violence.

3. How did the disclosure happen?

a. Did they come to your office hours?

i. If office hours, what topic did you cover that week in class?

ii. Which class was that student from?

b. Did they contact you by email?

i. If email, did you tell them to meet with you?

c. Did they contact you after class?

i. If class, what was the topic that day?

4. What did they tell you?

i. Go into as much detail about the experience as you remember (e.g., facial expressions, emotions, etc.)

5. Did they ask for your help?

6. Did they ask for considerations with grades/assignments?

7. Did they give a lot of detail about the incident?

8. Did they want information from you? If so, what kind?

9. How long did the conversation last?

10. Where did it occur?

11. How did you feel about the experience?

12. Did your student come to you in crisis?

13. Do you feel that they just wanted to tell the experience to someone or to you in particular?

14. How did you react when they told you?

15. Did you feel you were helpful? 
Keeping in mind that your answers are anonymous.

16. Do you feel you were harmful in any way?

17. Do you feel you were helpful in any way?

18. Do you think could have done more?

19. Was there anything you said that you think you should not have?

20. Was there anything you said you think you should have?

21. Why do you think they came to you?

22. What do you think their expectation was from the discussion?

23. What (if any) information did you give them?

24. Did you refer to them someone else?

25. Did you speak about this with anyone else, such as colleagues?

26. Did you recommend a rape crisis center?

27. Did they contact them that you know about?

28. Did you go with her or him to any appointments (rape crisis center, medical, housing issues)?

29. How did this experience impact your thoughts, feelings, beliefs?

30. Did this experience change your perception of safety?

31. Have you had more than one experience?

32. Are there any that stick out in your mind and why?

33. How did you handle this situation?

34. Have the way you have dealt with these experiences changed over time? If so, how?

35. Does the university have a policy on dealing with sexual assault?

36. Do you know what it is? Can you describe it?

37. What advice would you give a professor dealing with this for the first time?

38. What resources do you think would be helpful?

39. Do you have any other comments or thoughts that you would like to share about any of your experiences with students disclosing sensitive information?

Now we are about done but, of course, we need some background information on you.

Gender identification

Racial identification

Ethnicity identification

Political identification

Age

Thank you for your time and participation in this project. 


\section{Declaration of Conflicting Interests}

The author(s) declared no potential conflicts of interest with respect to the authorship and/or publication of this article.

\section{Funding}

The author(s) received no financial support for the research and/or authorship of this article.

\section{Note}

1. Founded in 1990, the purpose of The Clothesline Project is to educate, break the silence, and bear witness to violence against women. Women affected by violence decorate a shirt and then hang the shirt on a clothesline to be viewed by others as testimony to the problem of violence against women. Retrieved http://www.clotheslineproject.org/

\section{References}

Acker, S., \& Feuerverger, G. (1996). Doing good and feeling bad: The work of women university teachers. Cambridge Journal of Education, 26, 401-423.

Adler, E. (1984). It happened to me: How faculty handle student reactions to classroom material (Working paper 132). Wellesley, MA: Wellesley College, Center for Research on Women.

Ahrens, C. (2006). Being silenced: The impact of negative social reactions on the disclosure of rape. American Journal of Community Psychology, 38, 263-274.

Armstrong, E., Hamilton, L., \& Sweeney, B. (2006). Sexual assault on campus: A multilevel, integrative approach to party rape. Social Problems, 53, 483-499.

Astin, A. W., Dey, E. L., \& Korn, W. S. (1991). The American college teacher: National norms for the 2004-2005 HERI faculty survey. Los Angeles, CA: Higher Education Research Institute, UCLA.

Bachman, R. (1998). The factors related to rape reporting behavior and arrest: New evidence from the National Crime Victimization Survey. Criminal Justice and Behavior, 25, 8-29.

Bem, S. (1983). Gender schema theory and its implications for child development: Raising gender-aschematic children in a gender-schematic society. Signs: Journal of Women in Culture and Society, 8, 598-616.

Bromley, M. (1995). Comparing campus and city crime rates: A descriptive study. American Journal of Police, 14(1), 131-148.

Cass, A. (2007). Routine activities and sexual assault: An analysis of individual and schoollevel factors. Violence and Victims, 22, 350-366.

Day, A., \& Livingstone, H. (2003). Gender differences in perceptions of stressors and utilization of social support among university students. Canadian Journal of Behavioral Science, 35, 73-83.

DeKeseredy, W., \& Kelly, K. (1993). The incidence and prevalence of woman abuse in Canadian university and college dating relationships. Canadian Journal of Sociology, 18, 137-159.

Denzin, N., \& Lincoln, Y. (2003). Introduction: The discipline and the practice of qualitative research. In N. K. Denzin \& Y. Lincoln (Ed.), Collecting and interpreting qualitative materials (pp. 1-46). Thousand Oaks, CA: SAGE. 
DeVault, M. (1990). Talking and listening from a woman's standpoint: Feminist strategies for interviewing and analysis. Social Problems, 37, 96-117.

Durfee, A., \& Rosenberg, K. (2009). Teaching sensitive issues: Feminist pedagogy and the practice of advocacy-based counseling. Feminist Teacher, 19(2), 103-121.

Feldman-Summers, S., \& Norris, J. (1984). Differences between rape victims who report and those who do not report to a public agency. Journal of Applied Social Psychology, 14, 562-573.

Fisher, B., Cullen, F., \& Turner, M. (2000). The sexual victimization of college women (NCJ 182369). Washington, DC: National Institute of Justice.

Fisher, B., Cullen, F., \& Turner, M. (2002). Being pursued: Stalking victimization in a national study of college women. Criminology \& Public Policy, 1, 257-308.

Gamache, D. (1991). Domination and control: The social context of dating violence. In B. Levy (Ed.), Dating violence: Young women in danger (pp. 69-83). Seattle, WA: Seal.

Golding, J., Siege, J., Sorenson, S., Burnam, A., \& Stein, J. (1989). Social support sources following sexual assault. Journal of Community Psychology, 17, 92-107.

Hart, T. C. (2007). Violent victimization of college students: Findings from the National Crime Victimization Survey. In J. Sloan \& B. Fisher (Eds.), Campus crime: Legal, social, and policy perspectives (2nd ed., pp. 129-146). Springfield, IL: C.C. Thomas.

Hayes-Smith, R., Richards, T., \& Branch, K. (2010). “. . . But I'm not a counselor:” The nature of role strain experienced by female professors when a student discloses sexual assault and intimate partner violence. ELiSS, 2(3):ISSN: 1756-848X

Hoffman, M. L. (1977). Sex differences in empathy and related behaviors. Psychological Bulletin, 84, 712-722.

Humphrey, J., \& White, J. (2000). Women's vulnerability to sexual assault from adolescence to young adulthood. Journal of Adolescent Health, 27, 419-424.

Hutchinson, S., \& Wilson, H. (1994). Research and therapeutic interviews: A poststructuralist perspective. In J. M. Morse (Ed.), Critical issues in qualitative research methods (pp. 300-315). Thousand Oaks, CA: SAGE.

Karjane, H., Fisher, B., \& Cullen, F. (2002). Campus sexual assault: How America's institutions of higher education respond (NCJ 196676). Washington, DC: National Institute of Justice.

Kvale, S. (1996). Interviews: An introduction to qualitative research interviewing. Thousand Oaks, CA: SAGE.

Kvale, S., \& Brinkmann, S. (2009). Interviews: Learning the craft of qualitative research interviewing. Thousand Oaks, CA: SAGE.

Koss, M., Gidyez, C., \& Wisniewski, N. (1987). The scope of rape: Incidence and prevalence of sexual aggression and victimization in a national sample of higher education students. Journal of Counseling and Clinical Psychology, 55, 162-170.

Lindholm, J. A., Szelenyi, K., Hurtado, S., \& Korn, W. S. (2005). The American college teacher: National norms for the 2004-2005 HERI faculty survey. Los Angeles, CA: Higher Education Research Institute, UCLA.

Lofland, J., Snow, D., Anderson, L., \& Lofland, L. (2006). Analyzing social settings: A guide to qualitative observation and analysis (4th ed.). Belmont, CA: Wadsworth. 
Murphy-Geiss, G. (2008). Bringing the facts to life: Facilitating student engagement with the issue of domestic violence. Teaching Sociology, 36, 378-388.

Ptacek, J. T., Smith, R., \& Dodge, K. (1994). Gender differences in coping with stress: When stressor and appraisals do not differ. Personality and Social Psychology Bulletin, 20, 421-430.

Sable, M. R., Danis, F., Mauzy, D. L., \& Gallagher, S. K. (2006). Barriers to reporting sexual assault for women and men: Perspectives of college students. Journal of American College Health, 55, 156-162.

Sanday, P. R. (1996). A woman scorned: Acquaintance rape on trial. New York, NY: Doubleday.

Siegel, D., \& Raymond, C. (1992). An ecological approach to violent crime on campus. Journal of Security Administration, 15(2), 19-29.

Skovholt, T., Grier, T., \& Hanson, M. (2001). Career counseling for longevity: Self-care and burnout prevention strategies for counselor resilience. Journal of Career Development, 27, 167-176.

Starzynski, L. L, Ullman, S. E., Filipas, H. H., \& Townsend, S. M. (2005). Correlates of women's sexual assault disclosure informal and formal support sources. Violence and Victims, 20, 417-432.

Ullman, S. (1996). Do social reactions to sexual assault victims vary by support provider? Violence and Victims, 11, 143-157.

Volkwein, J., Szelest, B., \& Lizotte, A. (1995). The relationship of campus crime to campus and student characteristics. Research in Higher Education, 36, 647-670.

Wasco, S., Campbell, R., \& Clark, M. (2004). A multiple case study of rape victims advocates' self-care routines: The influence of organizational context. American Journal of Community Psychology, 30, 731-760.

West, C., \& Zimmerman, D. (1987). Doing gender. Gender and Society, 1, 125-151.

Yescavage, K. (1999). Teaching women a lesson: Sexually aggressive and sexually nonaggressive men's perceptions of acquaintance and date rape. Violence Against Women, 5, 796-812.

\section{Bios}

Kathryn A. Branch is an assistant professor in the Department of Criminology and Criminal Justice at the University of Tampa. Her current research focuses on the impact of sexual assault on secondary victims such as faculty and friends of survivors. Previous research has focused on the role of social support in women's use of aggression against an intimate partner.

Rebecca Hayes-Smith is an assistant professor in the Department of Sociology, Anthropology, and Social Work at Central Michigan University. Her research interests include violence against women, race, gender, and class issues in the criminal justice system and the media's influence on society. Her work is featured in the journals Critical Criminology and Contemporary Justice Review.

Tara N. Richards is a doctoral candidate in the Department of Criminology at the University of South Florida. Her research interests include violence against women, at-risk girls, and the intersection of gender, class, race, and crime. Currently, she is a research assistant in the Department of Mental Health Law and Policy at the Louis de la Parte Florida Mental Health Institute. Her teaching experience is in criminological theory and gender and crime. 